\title{
Prevalence of Khat (Catha edulis) Chewing and Its Determinants: A Respondent-Driven Survey from Hossana, Ethiopia
}

\author{
Riyaz Ahmad Rather' \\ Solomon Berhanu' \\ Lemma Abaynah' \\ Mohammed Sultan ${ }^{2}$ \\ 'Department of Biotechnology, College \\ of Natural and Computational Science, \\ Wachemo University, Hossana, Ethiopia; \\ ${ }^{2}$ Department of Statistics, College of \\ Natural and Computational Science, \\ Wachemo University, Hossana, Ethiopia
}

Background: Ethiopia is a leading khat producer in East Africa, and almost all regions are involved in khat production. Hossana, a small town in Southern Ethiopia, is also actively involved in khat production and its use. However, very few studies have been conducted to investigate the habit of khat chewing in this area. This study was conducted to assess the prevalence and predictors of khat chewing among Hossana residents.

Methods: The study was conducted on 1700 individuals in Hossana town from March 2018 to June 2019. A structured pre-tested self-administered questionnaire was designed and used for data collection. Descriptive statistics and logistic regression were carried out to study the prevalence and predictors of khat chewing in the study area.

Results: The overall prevalence of khat chewing among the respondents was $58.0 \%$ (95\% CI 53.4-63.3) of which $68.4 \%$ were daily khat users and $31.5 \%$ used it occasionally. About $24.7 \%$ of females and $75.2 \%$ of males had chewed khat. Muslim religion (AOR 2.37; 95\% CI 1.58-4.32), male gender (AOR 3.48; 95\% CI 2.16-5.61), Older age (AOR 1.36; 95\% CI 0.84-2.21), participants having habitual khat chewing friends or a khat chewer family associate (OR 1.70; 95\% CI 1.17-2.20) were found to be independent predictors of chewing. Conclusion: Significant portion of the population in the study area chew khat. Khat use is significantly associated with the Muslim religion, gender, age, and habit of family and friends. Further studies with larger demographic area are warranted from the study area to reproduce these findings.

Keywords: determinant factors, Hossana, khat, prevalence, religion

\section{Background}

Catha edulis is a small tree whose tender leaves and young buds are chewed to get a state of euphoria. The plant is mainly grown in different regions of Ethiopia, owing to its local and international demand. Countries like Yemen, Somalia and Kenya also cultivate this plant on a large scale to outsource other African and Middle Eastern countries. ${ }^{1}$ The plant is called by different names like khat or chat in Ethiopia, jaad in Somalia, qat or gat in Yemen. ${ }^{2}$ The colour of the leaves ranges from green, yellow and red depending upon the growth stage of the plant. The plant parts contain cathinone an amphetamine-like substance. Cathinone is oxidized to cathine within 72 hours of the harvest. Upon consumption cathine stimulates certain neurotransmitters of the brain like dopamine, norepinephrine and adrenaline that makes a user feel high. ${ }^{3,4}$ A small magnitude of pharmacological compounds like merucathine, phenylpentenylamines and pseudomerucathine are also found in khat
Correspondence: Riyaz Ahmad Rather Department of Biotechnology, College of Natural and Computational Science, Wachemo University, Hossana, 667, Ethiopia

Email riyazahmad@wcu.edu.et 
plant. ${ }^{5}$ Although World Health Organization has categorized the C. edulis leaves, buds and its active constituents as a drug of abuse, there are no legal sanctions on its production or use in Ethiopia. Hence, its production is growing faster in this country as families associated with its farming, consider it as a good source of income. ${ }^{6}$

In Ethiopia, khat production has increased from 796,520 units of $100 \mathrm{kgs}$ in 2001-2002 to 2,758,345 units of $100 \mathrm{kgs}$ in 2014-2015, accounting for it a secondmost exported item of Ethiopia after coffee. ${ }^{7}$ In Southern Ethiopia alone 22,570 hectares of land were used in 20032004 for khat production, which has grown to 69,505 hectares in 2014-2015, accounting for a 208\% increase in land used for khat production during this period. ${ }^{8,9}$ Higher market value, increase in consumption, improved export transmission, Government interventional policies, and easy production are some combined factors that contribute to the expansion of the khat production in Ethiopia mainland..$^{10,11}$ The boom in khat production has witnessed a significant socioeconomic implication. It is believed that khat is now one of Ethiopia's major resource of internal tax revenue. ${ }^{12}$ Revenue officials cite that khat like other export commodities, fetch millions of dollars earning annually through customized trade deals. The majority of the khat trade is domestic hence the tax is collected at different regional and zonal levels. The domestic tax collection augments the total export tax collection revenue owing to a big export market. ${ }^{13}$

Khat chewing is an old practice in different parts of eastern and western Africa, the Middle East and most Arabian Peninsula countries where the plant is widely disseminated. ${ }^{14}$ In Ethiopia, khat is widely used at social gatherings for stimulation and social recreation. Stimulation is usually attained by chewing the young buds and tender leaves privately or in small social gatherings. ${ }^{7}$ Increased appetite for social interaction, euphoria, excitement, increase in libido and levels of energy are some after-effects among khat chewing individuals. ${ }^{15,16}$ It is evident from various studies that khat chewing is also found in students and teachers to sound alert during exam preparations and to reduce fatigue after long working hours. Even farmers use it concomitantly to increase their work efficiency or performance. ${ }^{17}$

Even though khat chewing is popular among the masses, there is substantial evidence that khat chewing harms social, mental and physical wellbeing. ${ }^{18}$ Certain medical complications like adverse cardiovascular events, liver failure, stomach ulcers, depression and anxiety, psychosis, impotence, among others have been found associated with khat chewers. ${ }^{19}$ Certain social behaviors like smoking, use of drugs and alcohol have been implicated within the khat chewing populace. ${ }^{20}$ Despite these implications, Ethiopian law neither explicitly allow nor proscribe the cultivation, consumption, or sale of khat. Till now, the Ethiopian Government has no clear legislation on khat use, sale or production. Even with associated health risks, khat production is reported from different regions of Ethiopia, the South region is the second leading khat producer after Oromia. Even though few studies have been conducted on khat production, its use and prevalence among youth and adults in Ethiopia, but no study have been conducted, that have examined its pervasiveness in different sections of the community from the study area. The urban and rural communities of Hossana town and surrounding areas are engaged in khat production and its trade. Apart from khat cultivation, this town is a commercial hub of khat business. Farmers and khat users across regions carry a buying and selling process in the study area. The farmers from the study region contribute ample produce to the total production volume in Ethiopia. Altogether, the study area has a vast density of khat users who are either cultivators or consumers. Hence, evaluating its prevalence and using habits within the local inhabitants is warranted. No such studies have been conducted in the study area to date. Therefore, this study aimed to assess khat chewing habits and its determining factors among the local inhabitants of the Hossana population using a structured questionnaire.

\section{Methods}

\section{Study Setting and Design}

The study was conducted in Hossana town located 235 $\mathrm{Km}$ to the west of Addis Ababa, the capital city of Ethiopia. It has a latitude and longitude of $7^{\circ} 33^{\prime} \mathrm{N} 37^{\circ} 51^{\prime}$ E with an elevation of 2177 meters above sea level and is the administrative town of Hadiya zone. The latter is one of the administrative zones of the South region. According to the 2011 census, the town has a population of 89,300 individuals.

The cross-sectional study was conducted between March 2018 to June 2019 to assess the prevalence of khat chewing and its determinants. All willing individuals who were directly or indirectly involved with khat use or its production were included in the study. A convenience sampling technique was employed to recruit the study 
participants and the sample data was stratified based on the variables used in the questionnaire. The individuals who volunteered to participate in this study were briefed about the objectives of the study. All the responses to the questionnaire and the personal details like name, ethnicity, religion, etc., of the study participants, were kept confidential. Ethical approval from the ethical committee of the university was sought to include the study subjects in this study. All participants have provided written informed consent. All the data collected from the respondents were kept confidential and the anonymity of the subjects was maintained throughout the study. The University ethics committee approved the study (Memo no. WCU/ECC/ 2018/3210) and prior permission was sought from the local administration of the town to carry out this survey. The sample size was calculated using the power formula and the same was validated by GraphPad Prism 8.4.1.676. A $5.0 \%$ non-response rate was considered while validating the final sample number.

$$
\text { Sample size } \mathrm{n}=\widehat{\mathrm{p}} \widehat{\mathrm{q}}\left[\frac{\mathrm{Z}_{\alpha / 2}}{\varepsilon}\right]^{2}
$$

Where $n=$ sample size,

$$
\widehat{p}=\text { sample proportion, } \widehat{q}=1-\widehat{p},
$$

$\mathrm{Z}_{\frac{\alpha}{2}}=$ is confidence interval and $\varepsilon=$ margin of error.

All the data responses were collected under the supervision of a skilled data collector who was trained in data collection and field supervision.

\section{Data Collection and Recruitment of Subjects}

A pre-tested self-administered structured questionnaire was developed from the already published literature consisting of open and closed-ended questions. ${ }^{21}$ The questionnaire covered different questions regarding khat chewing habits and socio-demographic factors. The questionnaire was prepared in English language and was later translated into Amharic, the local language of the study area, by a language expert. Finally, the Amharic language questionnaire was used for data collection. Respondents were sampled from khat markets and shops, cafeterias, and households within the study area and instructed to respond to all the items of the questionnaire with a pen or a pencil. Upon completion, the questionnaire was handed over back to the data collector(s). To maintain consistency in translation, the questionnaire was again translated back into
English by a person(s) who was proficient in the EnglishAmharic translation. To check the authenticity of the translations, all the translations were carried by three individual anonymous translators or language experts. The questionnaire was pretested on 100 random khat users in the vicinity of the study area and subsequent corrections were made to improve the precision and exactness of some items in the questionnaire. The study participants were instructed to answer anonymously each question on the questionnaire. The identity of the study participants was kept confidential and each questionnaire was assigned a secret code.

\section{Statistical Analysis}

The data were analyzed using the latest version of GraphpadPrism 8.4.1.676. Different statistical assessments like bivariate and multivariate analyses, logistic regression, adjusted and unadjusted odds ratios (OR) and their 95\% confidence intervals (CI) were used as indicators of the strength of association between different variables. A p-value $<0.05$ was considered a cutoff level for statistical significance.

\section{Results}

Using a sample size calculation with a 3.5\% marginal error a sample size of 1700 individuals was significant enough to provide with questionnaires. All the study participants completed the questionnaires and returned them to the data collector. Of these, 1307 (76.8\%) were males and 393 (23.1\%) females. Although a $100 \%$ response rate was observed, few respondents were initially apprehensive to respond to certain demographic variable questions like ethnicity and religion. The mean (SD) age of the respondents was $24.4( \pm 1.6)$ years (Table 1$)$.

A total of 986 (58.0\%; 95\% CI 53.4-63.3\%) respondents chewed khat among which 675 (68.4\%) were daily users while $311(31.5 \%)$ use it occasionally. The remaining $714(42.0 \%)$ respondents were either associated with the khat business or act as middlemen during the selling or buying process. Among the latter group, a very nonsignificant $(7 / 714 ; 8.8 \%)$ number of respondents declared that they chew the khat once or twice a year during some festivals. A vast majority (89.0\%) of daily users reported chewing multiple times a day, and the rest reported chewing once a day. Around noon and evening is the favoured time of day for chewing. The majority of the respondents (56.5\%) enrolled during this study were from an urban area, whereas $43.4 \%$ were from the rural Hossana area. 
Table I Socio-Demographic Characteristics of the Study Population $(n=1700)$

\begin{tabular}{|c|c|c|}
\hline Variables & Frequency & Percent \\
\hline \multicolumn{3}{|l|}{ Sex } \\
\hline Male & 1307 & 76.8 \\
\hline Female & 393 & 23.1 \\
\hline \multicolumn{3}{|l|}{ Age } \\
\hline $20-29$ & 798 & 46.9 \\
\hline $30-39$ & 641 & 37.7 \\
\hline $40+$ (Forty years and above) & 261 & 15.3 \\
\hline \multicolumn{3}{|l|}{ Religion } \\
\hline Orthodox & 135 & 7.9 \\
\hline Protestant & 165 & 9.7 \\
\hline Catholic & 150 & 8.8 \\
\hline Muslim & 1188 & 69.9 \\
\hline Others* & 62 & 3.7 \\
\hline \multicolumn{3}{|l|}{ Education } \\
\hline Primarily Educated (up to 8th Grade) & 887 & 52.1 \\
\hline 9th-12th Grade & 133 & 7.8 \\
\hline Graduate and Postgraduate & 97 & 5.7 \\
\hline Uneducated & 583 & 34.2 \\
\hline \multicolumn{3}{|l|}{ Living with } \\
\hline Parents & 1638 & 96.3 \\
\hline Friends & 0 & 0.0 \\
\hline Relatives & 29 & 1.7 \\
\hline Alone & 33 & 1.9 \\
\hline \multicolumn{3}{|l|}{ Residence } \\
\hline Rural & 962 & 56.5 \\
\hline Urban & 638 & 43.4 \\
\hline
\end{tabular}

Note: *Others include those who did not reveal their religious identity.

Of the chewers, $92.6 \%$ chewed khat with some companion like a friend or a relative. Only $7.4 \%$ consume it lonely or when there is no one around. Most of the people $(99.7 \%)$ chewed it along with the water or some cold beverage and less than one percent $(0.2 \%)$ people used it with the stuff of their choice other than water and a cold beverage. During khat chewing, a proportionate number of study respondents (17.0\%) use alcohol and $3.1 \%$ smoke cigarettes. The study also revealed that an individual spends almost 27-30 ETB ( 1 ETB $=0.030$ USD, the exchange rate at the time of the study) $(p=0.003)$ per day on khat consumption. It has been observed that people who earn wages from some profession or job, spend 50-72 ETB per day $(\mathrm{p}=0.015)$. The majority of the respondents utilize their own earned money to buy the khat from the market but $17.5 \%$ of respondents declared that they borrow money from friends or take it from family members.

Upon validation, respondents provided a different reason for chewing khat. The majority $(73.0 \%)$ reported that they used khat to obtain maximum concentration. Socializing with friends and family members were given other reasons for khat use. Few respondents confirmed that they use khat to control emotions and to increase work efficiency. Small percentages $(2.3 \%)$ of respondents were unable to cite any reason for khat chewing. However, they confirmed that they like chewing khat and are addicted to its use.

The data were quantified using multivariate logistic regression to predict khat chewing based on independent variables. A significant regression equation was found $(\mathrm{p}<$ 0.001 ) with an $R^{2}$ of 0.785 . Our data suggest that male subjects had higher odds (AOR 3.48; 95\% CI 2.16-5.61) of khat chewing when compared with female subjects The odds of chewing khat increase many-fold with increasing age (Table 2). Religious faith has a significant influence on khat consumption. We established that khat use in Muslim respondents had several-fold higher odds (AOR 2.37; 95\% CI 1.584.32) when compared to other sects of religion (Table 2).

\section{Discussion}

We achieved a $100.0 \%$ response rate in our study, indicating the social desirability towards the current study. Though, few respondents were reluctant to respond to certain questions paving apprehensions of ethnic and religious disintegration in the society. Ethnicity and religion are considered as sacred and classified in the community irrespective of the followers of the religion or faith. Previous studies have also cited perceived anonymity as one of the reasons behind this irregularity. ${ }^{22}$

We witnessed a58.0\% of prevalence of khat chewing in this study. This is slightly a higher prevalence when compared with previously established data. Studies carried out from different regions of Ethiopia witnessed 31.0, 50.0 and 31.7 percentage prevalence, respectively. ${ }^{4,23,24}$ Most of the studies carried out earlier are either on a selected set of respondents like students or teachers only or have been carried out on variable sample numbers. The desirability of chewing khat among students and teachers is limited, as discussed in earlier studies. ${ }^{25-28}$ Hence a low prevalence rate is anticipated in these studies. Furthermore, all studies have a different and specific set of sample characteristics, 
Table 2 Logistic Regression Model Estimates of Risk Factors of Study Participants for Chewing Khat $(n=1700)$

\begin{tabular}{|c|c|c|c|c|}
\hline Variable & Odds Ratio (95\% Cl) & p-value & Adjusted Odds Ratio $(95 \% \mathrm{Cl})$ & p-value \\
\hline \multicolumn{5}{|l|}{ Sex } \\
\hline Male & $1.24(0.98-1.57)$ & 0.002 & $3.48(2.16-5.61)$ & $<0.001$ \\
\hline Female & 1.00 & & 1.00 & \\
\hline \multicolumn{5}{|l|}{ Age } \\
\hline $20-29$ & $\mathrm{I} .0 \mathrm{I}(0.8 \mathrm{I}-\mathrm{I} .23)$ & 0.060 & $1.05(0.65-1.70)$ & 0.013 \\
\hline $30-39$ & 1.00 & & 1.00 & \\
\hline$>40$ & $1.89(0.75-1.34)$ & $<0.001$ & $1.36(0.84-2.21)$ & 0.012 \\
\hline \multicolumn{5}{|l|}{ Education } \\
\hline $\mathrm{I}-8$ & $0.99(0.68-1.44)$ & 0.061 & $0.88(1.19-4.02)$ & 0.008 \\
\hline $9-12$ & 1.00 & & & \\
\hline Diploma & $1.00(0.53-1.33)$ & 0.133 & $1.02(0.97-2.12)$ & 0.003 \\
\hline Graduate and above & 0.98 & 0.651 & $2.05(1.19-2.36)$ & 0.153 \\
\hline \multicolumn{5}{|l|}{ Religion } \\
\hline Orthodox & $\mathrm{I} .0 \mathrm{I}(0.64-1.6 \mathrm{I})$ & 0.094 & $1.01(0.64-1.61)$ & 0.043 \\
\hline Protestant & 1.00 & & & \\
\hline Catholic & $1.07(0.64-1.57)$ & 0.097 & $1.14(0.72-0.96)$ & 0.853 \\
\hline Muslim & $1.93(0.72-3.15)$ & 0.003 & $2.37(1.58-4.32)$ & $<0.001$ \\
\hline Other* & $0.74(0.53-0.98)$ & 0.081 & $0.34(0.12-0.72)$ & 0.521 \\
\hline \multicolumn{5}{|l|}{ Living } \\
\hline Parents & $2.27(1.73-3.48)$ & $<0.001$ & $3.12(2.11-4.75)$ & $<0.001$ \\
\hline Relatives & 1.00 & & & \\
\hline \multicolumn{5}{|l|}{ Residence } \\
\hline Rural & $0.99(0.82-1.21)$ & 0.091 & I.I5 (0.57-2.34) & 0.05 \\
\hline Urban & 1.00 & & & \\
\hline
\end{tabular}

Note: *Others include those who did not reveal their religious identity.

methodological setup, demographic variables and approach towards khat chewing. This could be the rationale for the observed difference in khat chewing prevalence in our study.

The mean (SD) age for chewing khat in this study stands $24.4( \pm 1.6)$ years. This figure is variable in different studies carried on different kinds of respondents. In one study carried on high school students in Eastern Ethiopia, an age of 15.1 (2.33) years was observed as a starting age of chewing khat. ${ }^{21}$ In another study carried by Kebede Y (2002) on college students from northwestern Ethiopia, the starting age for chewing khat was found to be 17.3 (3.02) years. ${ }^{29}$ These observations indicate that respondents in our study have started chewing khat lately. It is a predominant fact that most of the studies carried on khat chewing prevalence have been conducted either on school pupils or college students who are in the 12-25 years, age group. The respondents enrolled in our study were either employed professionals or persons associated with the business. Furthermore, the local administration in the study area is campaigning about the legitimate use of khat chewing among the masses and the repercussions of chewing khat among adolescents and young children are widely discussed in the community. These cumulative factors might have impacted the khat chewing habits in the study area.

The odds of chewing khat in Muslims (AOR 2.37; 95\% CI 1.58-4.32) and males (AOR 3.48; 95\% CI2.16-5.61) (Table 2) respondents was found higher in this study when compared with other different religions and females, respectively. These findings are in concordance with earlier studies carried in different regions of Ethiopia. ${ }^{30-32}$ Studies carried out on school students in Saudi Arabia have reported similar findings. In their study, 
a significant difference in khat chewing was observed among the male and female respondents. ${ }^{15}$ Previously published literature also cites that the magnitude of khat chewing is higher in Muslims as compared to other religions. ${ }^{33,34}$ Gender and religion variable khat consumption among people may be due to the general tendency of male folklore to abuse substances compared to females and the larger cultural acceptance of male substance use in Ethiopia and other khat consuming countries. Although khat consumption is not specifically sanctioned by any religion, most Christians refrain from using it citing certain religious obligations. However, Muslims use it abundantly in social, cultural and personal gatherings. Additionally, the Muslim community is more involved in khat cultivation and production in the study area. Hence, the authors are of opinion that it could be the one reason for higher khat chewing prevalence among Muslims in the study area.

While previous studies have suggested that there is no specific time for khat consumption, ${ }^{35}$ but most of the respondents $(68.2 \%)$ in our study confess that evening and noon is the most favourable time to consume khat immediately after having a meal. During this study, the authors have witnessed small gatherings of friends at restaurants and khat selling shops where the chewing ceremony takes place. In our study, we also came across certain rooms which are specifically set up for the family to chew khat privately. Earlier studies have reported that such commercial and non-commercial khat chewing rooms are common in Ethiopia as well as countries such as Yemen and Kenya. ${ }^{3}$ In our study, we found that these rooms have entertainment facilities like television and music players with comfortable sitting facilities. However, no such facility or ambience was found in khat selling shops where some people prefer to chew khat.

It is a fact from the previously published literature that khat is always consumed in social gatherings along with family or friends with stuff like water, a cold beverage, alcohol, shisha or homemade drinks. ${ }^{36,37}$ Our findings are consistent with these observations. Our data established that the majority of respondents preferred khat chewing with friends or family. A high comfort level and costsharing standard might be the rationale behind chewing khat with family and friends, respectively. The least percentage $(7.4 \%)$ of respondents chewed it privately without family or friends. We observed that these respondents were in a 20-29 years age group who wish to consume khat in the absence of family members or friends to limit the social stigma. Parental control and surveillance on adolescents with substance use might be the reason for reduced khat usage among teenage groups.

In our study, we found that respondents spend money differently on khat consumption. One set of respondents avail different services like a private room, alcohol, water or another food item along with khat. They spend more than 50 ETB per day to avail all these services, whereas another set of respondents who are financially dependent on family or borrow money from friends spend less than 30 ETB per day on khat consumption without availing any additional services. Money is a predominant deciding factor for the odds of khat chewing. A meta-analysis carried by GantinetAyano et al (2019) reported that persons who earn more and are financially independent spend more on khat use than others who are financially non-self reliant. ${ }^{38}$ Hence, the source of income has a greater impact on khat consumption.

Although in this study we have not measured or evaluated any health risks of khat chewing in the respondents, citable literature suggests associated health risks of khat chewing. ${ }^{18-20}$ Hence this study reinforces the need for regulation and highlights the need for optimal use of khat to minimize the health risks. The policymakers and regulators can take a cue from the findings of this study to formulate a production cum usage model which can have balance points between khat consumption and production. The authors recommend a sustainable model in the interest of khat growers which simultaneously can highlight the ill effects of irrational khat use.

There are a few limitations associated with this study. The major limitation of the current study is the small sample size. A bigger sample size with a larger study area could influence the estimated report. Furthermore, the study also employed a cross-sectional research method which did not show the causal relationship among variables. Impacts of khat use were only the perceived and experiences of the participants. Additionally, due to the cross-sectional nature of the study design, this study could not establish a causeand-effect relationship between the variables.

\section{Conclusion}

The study concludes that khat chewing is prevalent among people in the study area. Khat chewing among individuals is significantly associated with peer influence, male gender, income, khat chewing habit among friends and family members, and being a Muslim. Money is a key deciding factor in the odds of chewing khat and individuals spend differently 
on khat chewing. Although there is no specific time to consume the khat, noon and evening were the preferred time to utilize the khat, while social gatherings were found to be the hot spots of khat chewing. Substances like water and beverages were the desired items that were consumed along with khat. A prospective longitudinal study deliberating on frequency and risk factors associated with khat consumption is recommended. Furthermore, the authors are of opinion that an appropriate design study with the inclusion of more targeted people is warranted so that the social and health consequences are assessed.

\section{Abbreviations}

CI, confidence interval; ETB, Ethiopian Birr; USD, United States Dollar; OR, odds ratio; AOR, adjusted odds ratio; $\mathrm{SD}$, standard deviation.

\section{Data Sharing Statement}

The data set generated during this study is available with the corresponding author on a reasonable request.

\section{Ethics Approval and Informed Consent}

The ethical committee of the Wachemo University approved the study protocol (Memo no. WCU/ECC/ 2018/3210). The study was conducted in accordance with the Helsinki declaration. All participants have provided written informed consent.

\section{Acknowledgments}

The authors thank Wachemo University for the logistic support. Our sincere thanks to all study participants and data collectors who actively participated in this study.

\section{Disclosure}

The authors report no conflicts of interest in this work.

\section{References}

1. Kalix P. Khat: scientific knowledge and policy issues. Br J Addict. 1987;82(1):47-53. doi:10.1111/j.1360-0443.1987.tb01436.x

2. Odenwald M, Klein A, Warfa N. Introduction to the special issue: the changing use and misuse of khat (Catha edulis)-tradition, trade and tragedy. J Ethnopharmacol. 2010;132(3):537-539. doi:10.1016/j. jep.2010.11.012

3. Al-Motarreb A, Baker K, Broadley KJ. Khat: pharmacological and medical aspects and its social use in Yemen. Phytother Res. 2002;16 (5):403-413. doi:10.1002/ptr.1106

4. Belew M, Kebede D, Kassaye M, Enquoselassie F. The magnitude of khat use and its association with health, nutrition and socio-economic status. Ethiop Med J. 2000;38:11-26.
5. Manuela G, Michele S, Paolo N. Khat chewing from the pharmacological point of view: an update. Subst Use Misuse. 2008;43 (6):762-783. doi:10.1080/10826080701738992

6. Kalix P. Cathinone, a natural amphetamine. PharmacolToxicol. 1992;70:77-86.

7. Cochrane L, O'Regan D. Legal harvest and illegal trade: trends, challenges, and options in khat production in Ethiopia. Int J Drug Policy. 2016;30:27-34. doi:10.1016/j.drugpo.2016.02.009

8. Bezu S, Holden S. Are rural youth in Ethiopia abandoning agriculture? World Dev. 2014;64:259-272. doi:10.1016/j.worlddev.2014.06.013

9. Central Statistical Agency. Agricultural Sample Survey 2014/2015, Area and Production of Major Crops. Vol. 1. Addis Ababa: Central Statistical Agency, Federal Democratic Republic of Ethiopia; 2015.

10. Belwal R, Teshome H. Chat exports and the Ethiopian economy: opportunities, dilemmas and constraints. Afr $J$ Bus Manag. 2011;5:3635-3648.

11. Gemech F, Struthers J. Coffee price volatility in Ethiopia: effects of market reform programmes. J Int Dev. 2007;19(8):1131-1142. doi: $10.1002 /$ jid. 1389

12. Gebissa E. Scourge of life or an economic lifeline? Public discourses on khat (Catha edulis) in Ethiopia. Subst Use Misuse. 2008;43 (6):784-802. doi:10.1080/10826080701738950

13. Feyisa TH, Aune JB. Khat expansion in the Ethiopian highlands. $M t$ Res Dev. 2003;23(2):185-189. doi:10.1659/0276-4741(2003)023 [0185:KEITEH]2.0.CO;2

14. Al-Mugahed L. Khat chewing in Yemen: turning over a new leaf. Bull World Health Organ. 2008;86(10):741-742. doi:10.2471/ BLT.08.011008

15. Ageely HM. Prevalence of Khat chewing in college and secondary (high) school students of Jazan region, Saudi Arabia. Harm Reduct J. 2009;6(1):11. doi:10.1186/1477-7517-6-11

16. Kalix P. Khat: a plant with amphetamine effects. J Subst Abuse Treat. 1988;5(3):163-169. doi:10.1016/0740-5472(88)90005-0

17. Jager AD, Sireling L. Natural history of khat psychosis. Aust NZJ Psychiatry. 1994;28(2):331-332. doi:10.3109/00048679409075648

18. Corkery JM, Schifano F, Oyefeso A, et al. 'Bundle of fun'or 'bunch of problems'? Case series of khat-related deaths in the UK. Drugs. 2011;18:408-425.

19. Gashawa A, Getachew T. The chemistry of khat and adverse effect of khat chewing. Am Sci Res J Eng Tech Sci. 2014;9:35-46.

20. Tesfaye F, Byass P, Wall S, Berhane Y, Bonita R. Association of smoking and khat (Catha edulis Forsk) use with high blood pressure among adults in Addis Ababa, Ethiopia. Prev Chronic Dis. 2008;5:1-11.

21. Reda AA, Moges A, Biadgilign S, Wondmagegn BY. Prevalence and determinants of khat (Catha edulis) chewing among high school students in eastern Ethiopia: a cross-sectional study. PLoS One. 2012;7(3):e33946. doi:10.1371/journal.pone.0033946

22. Smith TW. The hidden 25 percent: an analysis of nonresponse on the 1980 general social survey. Public Opin Q. 1983;47(3):386-404. doi: $10.1086 / 268797$

23. Tadesse M. Substance abuse and sexual HIV-risk behaviour among Dilla University students, Ethiopia. Educ Res. 2014;5:368-374.

24. Alem A, Kebede D, Kullgren G. The prevalence and socio-demographic correlates of khat chewing in Butajira, Ethiopia. Acta Psychiatr Scand. 1999;397:84-91. doi:10.1111/j.16000447.1999.tb10699.x

25. Damena T, Mossie A, Tesfaye M. Khat chewing and mental distress: a community based study, in Jimma City, Southwestern Ethiopia. Ethiop J Health Sci. 2011;21(1):37-45. doi:10.4314/ejhs.v21i1.69042

26. Deressa W, Azazh A. Substance use and its predictors among undergraduate medical students of Addis Ababa University in Ethiopia. BMC Public Health. 2011;11(1):660. doi:10.1186/1471-2458-11-660

27. Abdeta T, Tolessa D, Adorjan K, Abera M. Prevalence, withdrawal symptoms and associated factors of khat chewing among students at Jimma University in Ethiopia. BMC Psychiatry. 2017;17(1):142. doi:10.1186/s12888-017-1284-4 
28. Kassa A, Wakgari N, Taddesse F. Determinants of alcohol use and khat chewing among Hawassa University students, Ethiopia: a cross sectional study. Afr Health Sci. 2016;16(3):822-830. doi:10.4314/ahs.v16i3.24

29. Kebede Y. Cigarette smoking and khat chewing among university instructors in Ethiopia. East Afr Med J. 2002;79(5):274-278. doi:10.4314/eamj.v79i5.8869

30. Adane WG, Alemie GA, W/yhonnes SM, Gelaw YA. Prevalence and associated factors of khat use among university students in the University of Gondar, Northwest Ethiopia. J Subs Use. 2017;22 (2):176-181. doi:10.3109/14659891.2016.1166273

31. Gelaw Y, Haile-Amlak A. Khat chewing and its socio-demographic correlates among the staff of Jimma University. Ethiop J Health Dev. 2004;18:179-184.

32. Mekonen T, Fekadu W, Mekonnen TC, Workie SB. Substance use as a strong predictor of poor academic achievement among university students. Psychiatry J. 2017;2017:7517450. doi:10.1155/2017/7517450
33. Nutt D, King LA, Saulsbury C, Blakemore C. Development of a rational scale to assess the harm of drugs of potential misuse. Lancet. 2007;369 (9566):1047-1053. doi:10.1016/S0140-6736(07)60464-4

34. Room R. Multicultural contexts and alcohol and drug use as symbolic behaviour. Addict Res Theory. 2005;13(4):321-331. doi:10.1080/ 16066350500136326

35. Hussain M. Health and soci-economic Hazard associated with khat consumption. J Fam Community Med. 2013;15:3-11.

36. Omolo OE, Dhadphale M. Alcohol use among khat (Catha) chewers in Kenya. $\mathrm{Br} J$ Addict. 1987;82(1):97-99. doi:10.1111/j.13600443.1987.tb01442.x

37. Selassie SG, Gebre A. Rapid assessment of drug abuse in Ethiopia. Bull Narc. 1996;48:53-63.

38. Ayano G, Yohannis K, Abraha M. Epidemiology of khat (Catha edulis) consumption among university students: a meta-analysis. BMC Public Health. 2019;19(1):150. doi:10.1186/s12889-019-6495-9

\section{Publish your work in this journal}

Substance Abuse and Rehabilitation is an international, peerreviewed, open access journal publishing original research, case reports, editorials, reviews and commentaries on all areas of addiction and substance abuse and options for treatment and rehabilitation. The manuscript management system is completely online and includes a very quick and fair peer-review system. Visit http://www.dovepress. com/testimonials.php to read real quotes from published authors. 